\title{
APORTACIONES AL TRAZADO DE LA VÍA 19 DEL ITINERARIO DE ANTONINO A SU PASO POR GALICIA
}

\section{A CONTRIBUTION TO THE LAYOUT OF ROUTE 19 OF ANTONINUS ITINERARIUM IN GALICIA}

\author{
por \\ BENITO SÁEZ TABOADA
}

\begin{abstract}
No recuerdo...
Ya no viene el cavador que cavaba en el venero.

No recuerdo...

Sobre la mina han caído mil siglos de suelos nuevos. No recuerdo..

El mundo se acabará.

No se encontrará el secreto.

Juan Ramón Jiménez
\end{abstract}

Con este artículo me sumo al Homenaje a D. Manuel Pellicer Catalán, un antiguo y querido profesor de quien guardo muy gratos y buenos recuerdos.

RESUMEN En el presente artículo pretendemos dar a conocer a través de las fuentes antiguas, medievales y modernas, el marco geográfico, los restos arqueológicos, inscripciones, asentamientos, estudios precedentes,..., el hipotético trazado de la vía 19 del Itinerarium provinciarum Antonini Augusti a su paso por Galicia (España).

\begin{abstract}
In this article, we will try to inform you through ancient sources, those of the medieval age and the modern ones; through the geographical setting, the archeological ruins, inscriptions, settlements, previous sunveys and studies and so forth, the hypothetic layout of the route 19 of the Itinerarium provinciarum Antonini Augusti of the across Galicia (Spain)
\end{abstract}

Palabras claves Vías romanas. Itinerarium Provinciarum. Antonini Augusti.

Key words Roman roads. Itinerarium Provinciarum. Antonini Augusti. 
El Itinerarium provinciarum Antonini Augusti conocido comúnmente como el Itinerario de Antonino, es una de las fuentes itinerarias que más controversias ha ocasionado, ocasiona (autor, cronología, carácter del documento, trazados, situación de las mansiones, ...) y ocasionará a lo largo del tiempo (Roldán 1975: 19-101). El documento recoge 372 vías terrestres repartidas por todo el Imperio, 34 de las cuales corresponden a Hispania y tres de ellas $(18,19$ y 20) a la región gallega, siendo la vía 19 o Item a Bracara Asturicam a su paso por la actual Galicia sobre la que centraremos nuestro estudio a fin de determinar su hipotético trazado, y por consiguiente la disposición de sus mansiones. Asimismo, esperamos que dicho estudio sirva de ayuda a futuras investigaciones relacionadas tanto con el Itinerario como con la red viaria en general.

Vía 19 - Item a Bracara Asturicam

Wess.

\begin{tabular}{|c|c|c|c|c|}
\hline \multirow[t]{3}{*}{429} & 5 & Item a Bracara Asturicam & m.p. & CCXCVIIII, sic: \\
\hline & 6 & Limia & m.p. & $X V I I I I$ \\
\hline & 7 & Tude & m.p. & XXIIII \\
\hline \multirow[t]{11}{*}{430} & 1 & Burbida & m.p. & $X V I$ \\
\hline & 2 & Turoqua & m.p. & $X V I$ \\
\hline & 3 & Aquis Celenis & m.p. & $X X I I I I$ \\
\hline & 4 & Tria & m.p. & $X I I$ \\
\hline & 5 & Assegonia & m.p. & $X I I I$ \\
\hline & 6 & Brevis & m.p. & $X X I I$ \\
\hline & 7 & Marcie & $m . p$. & $X X$ \\
\hline & 8 & Luco Augusti & m.p. & $X I I I$ \\
\hline & 9 & Timalino & m.p. & $X X I I$ \\
\hline & 10 & Ponte Neviae & m.p. & $X I I$ \\
\hline & 11 & Uttaris & $m . p$. & $X X$ \\
\hline
\end{tabular}

Será a mediados del siglo XIX, concretamente en 1862, cuando aparezca la primera comunicación centrada en los caminos romanos a cargo de Saavedra (1863), quién sostiene que la vía 19 del Itinerario Antonino proveniente de Limia (Limia) penetra en nuestra región por Tui (Tude), llega a Pazos de Borbén (Burbida) por la orilla derecha del Miño y el valle del Tea. Con dirección norte prosigue por Tourón (Turoqua), Caldas de Reyes (Aquis Celenis) y Padrón (Iria) hacia Lugo por Mellid (Brevis) y Puente de Menjaboy (Marcie) próximo a Marzán. En Luco Augusti enlaza con la vía 20 o per loca maritima del mismo itinerario para seguir al sur por Baralla (Timalino), Los Nogales (Ponte Neviae) y Ruitelan (Uttaris).

Años más tarde Barros Silvelo (1875: 163-165) traza la ruta desde Tui (Tude) por Páramos, Guillarei, ladera oriental del Monte Faro, Almuiña, este del monte Padrós y Borbén o Burbida para seguir al oriente de los montes de Junqueira hacia Tourón o Turoqua. Próxima a Sacos prosigue por Moimenta, Couso, Moraña y norte de Peña Vicuda para llegar a Aquis Celenis o Caldas de Reyes, donde continúa entre Estacas y Cesar, sur del monte Gesteiras y Cesures dirección Iria o Tria. Alcanza Assegonia por Requeijo, Barcala, Couso, cruza de nuevo el Ulla por puente Vela-Bea, y prosigue entre Vilariño y Baamonde, montes de la Susana y Lamas, Gastrar, cercanías del Burgo y el Pino hasta Oines o Asseconia, desde donde encauza la ruta por Villadavil, Golán y montes de Gondollín hasta San Salvador de Abeancos (próximo a Melide) o Brevis. 
Avanza por Portela de Seixas, región del río Ferreira, Marzán o Martiae, orillas del Zamay, montes de Gomelle y Calde hasta Luco Augusti. Continúa por los montes de Recemil y Castrillón, margen del río Tordia, Franqueira y montes de Santa Cruz hasta Bertelín de Neira o Timalino. La vía sigue por las huellas de una calzada antigua por el valle de Jusá, siguiendo la falda oriental de la Pena del Pico, Tortes y Ferreiros de Balboa, en dirección al nacimiento del Cruzul y por Doncos a Ponte Neviae. Continuando el curso de este río en dirección al nacimiento pasando por Noceda, se encuentran los restos de un camino poco transitado, que sigue con bastante uniformidad las sinuosidades de los montes de San Pedro, La Faba y Lindoso para tomar el curso del Valcárcel en Ruitelan donde sitúa Uttaris.

Para Blázquez (1923: 10-18) la vía parte de Tui (Tude), discurre por Porriño, Mos, el valle de Louredo, Borbén (Burbida), río Oitaben y Tourón (Turoqua); continúa por el puente del río Almofrey, cerca de Bora, Fraga, Tenorio, Campo, Couso, proximidades de Lage y Caldas de Cuntis (Aquis Celenis). Prosigue por Valga, Padrón (Pria), donde la milla romana adopta la longitud de $1.666 \mathrm{~m}$. hasta Lugo, y sigue dirección Carcacia, Aixón (Aseconia), cruza el puente de Fojanes sobre el río Lana, además de los de Carballo, Cornado y Beigondo al pasar el río Iso en cuyas proximidades ubica Brevis. Sin variar la dirección de los afluentes del Ulla por su margen derecha, continúa sobre las corrientes del Baroza, Furelos, Choren y Fambre hasta Marzán o Martiae. Tras determinar el tramo Marcie-Luco Augusti por el puente de Meyjaboy describe el trazado desde la capital del Conventus hasta Timalino (Villartelín, cerca de Baralla. Las ruinas están cerca de Campo de Árbol) en dirección contraria al Itinerario de Antonino, es decir, considera que a partir de Campo de Árbol casi coincide con la carretera hasta Lugo, por Vega de Ampuero y proximidades de Bóveda. Desde Campo de Árbol, si seguimos la dirección del Itinerario, dirige la ruta por Gatín (Ponte Navias), Estrada, Villafriul, Quirogal, San Martín, cerca de Mosteiro, Fabol, Potorrión, Río de Noval, Villaespasantes, Mariño, Sedo, Río Montes, Comeal y Vega de Valcárcel (Uttaris).

En el trabajo de Monteagudo (1951: 202-215) a inicios de los años 50, se dibuja la ruta desde Tui (Tude) por Mos, Sajamonde (Turoqua), Redondela, Pontevedra, Caldas de Reyes y Padrón (Tria) para continuar por Cruces, Faramello, Sabugueiro (Assegonia), Gonzar, Sabugueira y Vitriz (Brevis) desde donde la dirige por Marzán (Marciae) hacia Luco Augusti. Hasta Vega de Valcárcel plantea dos rutas, una de acuerdo con la propuesta por Blázquez (1923: 11) y otra por Sarria, Teguín y Nogales que identifica con Pons Navia.

El estudio de Filgueira Valverde (1954-56: 27), centrado en la provincia de Pontevedra, traza la vía desde Tui (Tude) por Guillarei, Cristiñade, Ponteareas, Pías, Pazos de Borbén (Burbida), Tourón (Turoqua), Borela, Viascón y Campolameiro hasta Caldas de Reyes (Aquis Celenis).

Estefanía Álvarez (1960: 51-53) en su trabajo de investigación sobre las vías romanas de Galicia, diseña la vía 19 de Antonino a partir de Tui (Tude) dirección Páramos, Guillarei, cruza el río Arentey (lugar de Finolledo) y el Casetas, se dirige hacia Angoares, Ponteareas, el puente de Cons, Pías, Riofrío y Borbén (Burbida) donde toma rumbo norte. Cruza el río Oitaben y continúa por Parada, Tourón (Turoqua), Bora, donde atraviesa el Almofrey y por Tenorio, próxima a San Andrés de Geve, llega a Sacos. A través de Moimenta, Couso, Moraña, Cequeril y Lage, pasando por Pena Vicuña se dirige a Cuntis (Aquis Celenis). Prosigue por Portela, Pontevea (donde cruza el Ulla), la Gándara (San Félix de Sales), proximidades del monte llicino o Pico Sacro y Aixón (Sergude, Boqueixón) donde sitúa Pria. Después ordena la ruta por Gastrar, Lamas, Burgo, Castrofeito, Gonzar, El Pino, Oines y Asseconia en la zona de Arzúa, donde continúa hasta Luco Augusti por Boente, Mellid, Furelos (Brevis), Palas de Rey, Marzán (Martiae) e orillas del río Zamay. Desde Luco Augusti seguía por Santa Eulalia de Bóveda, Vega de Ampuero, Pepín, Campo de Árbol donde sitúa con ciertas reservas Timalino y Gatín (Pons Naviae), para proseguir tras cruzar el Navia por Estrada, San Martín de la Cañas y Ambas Mestas.

En los años 70, Ares Vázquez (1977-78: 3-7) en su trabajo sobre la mansión romana de Ponte Martiae establece el itinerario desde la provincia de La Coruña por Santiago de Vilouriz, monte Careón, S. Salvador de Merlán, San Jorge de Aguas Santas y Ponte Ferreira o Marcie, para seguir a Luco Augusti, tomando 
a Madoz (1845) como referencia, por Sta. María de Pacio, S. Román de Retorta, S. Pedro de Mera, S. Miguel de Bacurín, S. Martín de Poutomillos, S. Vicente del Burgo, S. Juan del Alto, S. Vicente de Veral, Santiago de Piugos, Louzareta, S. Lázaro del Puente y el puente sobre el Miño.

Los estudios de Arias Bonet (1987: 14-26.80; 1988: 15-18; 1989: 7-10) llevan el recorrido desde Tui (Tude) por Gondomar, Valladares, Vigo, Redondela y Arcade o Turoqua. Continúa por Pontevedra, Barro, Moraña y Cuntis (Aquis Celenis) para cruzar el río Gallo en Anllada, y proseguir por Casa da Cruz, Brea, Estrada y Puente Ledesma hasta la feligresía de San Miguel de Moreira donde en un lugar llamado "Pía y Pica" emplaza Pria. Desde San Miguel de Moreira ${ }^{1}$ (Pria) esboza la vía por Puente Basebe, Nuevefuentes, Turces, Nuestra Señora del Viso en Dombodán (Arzúa) o Asseconia, Mellid (Brevis) y San Román de Retorta (Marcie) hasta Luco Augusti.

En el trabajo de Peña Santos (1990-91: 217-243) sobre las vías romanas en la provincia de Pontevedra traza la ruta desde Tui (Tude) a través de la Depresión Meridiana por Vilar de Enfesta (Burbida), O Padrón (Sagamonde, Redondela), Arcade y Pontevedra (Turoqua) en base a tres miliarios con indicación de distancia localizados en Sagamonde (Redondela), Arcade (Sotomaior) y el puente de O Burgo (Pontevedra). Desde Pontevedra (Turoqua) continúa por Caldas de Reyes (Aquis Celenis) e Iria Flavia (Iria). El problema de las de XXIIII millas - 36 km.- que marcan el Itinerario de Antonino; es decir, $15 \mathrm{~km}$. más que los actuales, o, lo que es lo mismo, diez millas por encima de los esperados que existen entre Pontevedra (Turoqua) y Caldas de Reyes (Aquis Celenis), lo atribuye a los frecuentes errores del documento, con lo cual el error habría consistido en la adición involuntaria de una $\mathrm{X}$ a la cifra que marca la distancia entre Turoqua y Aquis Celenis, con lo que las XIIII millas correctas se habrían convertido en las XXIIII. Afirma el autor que hecha esta corrección, el Itinerario se nos muestra dotado de una asombrosa precisión, al menos para el tramo que nos ocupa.

\section{Bracara Augusta-Uttaris en la vía 19 (Item a Bracara Asturicam) del Itinerario Antonino(Sáez 2000).}

De acuerdo con los $1.480 \mathrm{~m}$. como valor métrico de la milla romana (Sáez 2001a: 31-33), la vía procedente de Bracara Augusta (Braga) tras superar Limia (Ponte de Lima) se adentra en la región gallega por Tui (Tude).

\section{Tude-Burbida ${ }^{2}$}

Desde Tui (Tude) toma dirección norte por Calzada, Porteliña ${ }^{3}$ (Ferreira 1988: 86) y Manteigada para cruzar el río Louro por el puente del mismo nombre o de la Veiga (Alvarado 1989: 398), donde se descubrió

1. El autor presenta las distancias y nombres tomados del manuscrito Parisinus Regius 4807 de finales del siglo IX, mientras que la edición de Cuntz, edición por nosotros empleada se basa en el manuscrito Parisinus Regius 7230A del siglo X:

$\begin{array}{lll}\text { AQUIS CELENIS } & \text { (G.Ar.) } & \text { (Cuntz) } \\ \text { PRIA } & \text { XII } & \ldots \\ \text { ASSECONIA } & \text { XXII (TRIA) } \\ \text { BREVIS } & \text { XII } & \text { XIII (ASSEGONIA) } \\ \text { MARCIE } & \text { XX } & \text { XX } \\ \text { LVCO } & \text { XIII } & \text { XIII }\end{array}$

2. Hojas $260-261,223$ y 224. Escala 1:50.000. Servicio Geográfico del Ejército.

3. Documentos de la catedral de Tuy hacen referencia a un camino que se dirigía a dicha localidad. 
un miliario de Claudio (Filgueira y García 1954-56: 196). Continúa por Gándara, Cerquido, Casal, Vacaría, Eidos e Insuas hasta Chan de Mielo. Al este de dicho trazado en Taboexa se ha probado la existencia de un castro romanizado, Coto de Altamira, con restos de ánforas, cerámica romana y objetos de bronce (Acuña y García 1975: 127-191; Gorges 1979: 343; Naveiro 1991: 240-252).

Prosigue por Chans, Costa de Sequeiros al oeste del castro de Batallans (Valverde 1957: 41), Proviso, Cruz y Alemparte hasta Ponteareas en cuyas proximidades apareció un tesorillo con monedas que abarcan desde la República a Trajano (Centeno 1987: 67). Cruza el río Tea por el puente viejo de los Remedios (Alvarado 1989: 151-155, 394) y se dirige por Gándara, Ferreiros, Souto y Chans en cuyas inmediaciones se encuentra un castro ${ }^{4}$ (Valverde 1957: 41), hasta Mondariz o Burbida donde se hallaron restos de pilas y cañerías antiguas de un probable balneario romano (Filgueira y García 1954-56: 189; Diez 1985: 93; Cruz 1986: 187) y cuyas aguas ferruginosas carbonatadas, poseen un valor terapéutico y cultual que se manifiesta en el centro y noroeste peninsular (Oró 1995: 332). A ello debemos añadir la existencia de varios asentamientos castreños en Covelo (Valverde 1957: 39-40) y la escasa distancia a la que se encuentra el castro de Troña con abundantes materiales romanos (Hidalgo 1995: 37).

\section{Burbida-Turoqua ${ }^{5}$}

Desde Burbida (Mondariz) alcanza el Tea que cruza por el puente de Cernadela (Alvarado 1989: 157-162, 393) donde existe "una calzada de acceso que responde al típico patrón romano" (Ferreira 1988: 94). Sigue por San Miguel, Quintans al este del castro de Piñeiro con doble recinto fortificado (Valverde 1957:40) y A Rúa, donde encontramos restos de una calzada, hasta Portacurbo para seguir hacia el río Oitavén por Festín, Gorgoeiros, Moscoso y Corujeira.

El río Oitavén "no tiene puente. Pasase allí el río Ançeu por Pasales, pero algo arriba, medio cuarto de legua, había no ha mucho y hoy se ven ruinas de un puente que llaman Porto Souto, y acaso iría por allí la estrada romana" (Martín 1975: 113). Otro documento recoge "Hoy se pasa el río Anceu a vado, pero en lo antiguo había allí a medio quarto de legua un Puente, y cuyas ruinas existen, y se llamaba el Puente del Porto Souto. Por ese Puente seria entonces la vereda para ir á pasar el Puente del río Caldelas, que aun se conserva" ${ }^{6}$. Tras superar el Oitavén la ruta se prolonga por Eidos de Arriba, Costiña, Rebordelo y por Colvelo a Puente Caldelas o Turoqua, donde están documentados la presencia de restos de calzada, una posible población romana (Ceán 1892: 223; Filgueira y García 1959: 81) y la existencia de tres manantiales de aguas frías (Oró 1995: 706).

\section{Turoqua-Aquis Celenis $^{7}$}

La calzada sale de Turoqua (Puente Caldelas) dirección noreste por Gruñas, Paradela, Senra y Pazos hasta el puente Borela del siglo XV sobre el río Almofrey (Alvarado 1989: 389). Al oeste del puente más concretamente en el castro de Bora apareció una moneda de Cómodo (Centeno 1987: 111).

Hacia el septentrión discurre por Laje, Outeiral y Cal donde se le une el camino medieval que de Pontevedra se dirigía a la tierra de Orellón y que utiliza la vieja ruta romana por San Pedro de Tenorio (Ferreira 1988: 110), para seguir por Cabanelas, Quintán, Valiño y Atalaya. Se ha localizado a poniente de este tramo, en OCoto

\footnotetext{
4. El castro domina el paso natural entre los valles de Puenteareas y Mondariz.

5. Hojas 224 y 186. Escala 1:50.000. Servicio Geográfico del Ejército.

6. AHN Melón 1438/10 (Ms 263 de la Univ. de Santiago, fol. $21 \mathrm{v}^{\circ}$ ).

7. Hojas 186,185 y 152. Escala 1:50.000. Servicio Geográfico del Ejército.
} 
(Geve), un tesorillo con monedas de finales del s. I hasta el s. IV (Fariña 1972: 115) y el fragmento de una inscripción en Cotobade (CIRG, II, 132) al oriente del camino.

Sin variar su curso se prolonga bordeando el río Lérez a $100 \mathrm{~m}$ de altitud evitando así las posibles inundaciones y avenidas de la corriente. Cruza el cauce en el puente de la Betarra del que no existen restos y continúa hasta Campo Lameiro en cuyas inmediaciones se encuentra el castro de Penalba (Álvarez 1991: 37-42). Atraviesa las poblaciones de Lameiro, Rendal, Couso, Contes, Casal, y el puente de Taboada (Alvarado 1989: 390), desde donde continúa por "una calzada de solo 1,80 o 1,90 m de anchura que lleva para que quede plana contra la pronunciada vertiente de la ladera en que está, una muralla que la sostiene en la parte que da al río y para que no cayesen a él los carros ni personas, colocaron además en algunos trozos de lajas que se levantan 10 y 20 centímetros sobre el plano de la vía" (García 1916b: 290).

Prosigue hacia Fontecova, Meira, y Cuntis o Aquis Celenis donde tenemos constancia de restos de época romana e inscripciones votivas dedicadas a las Ninfas (García 1916a; Filgueira y García 1954-56: 175; Centeno 1987: 133; Naveiro 1991: 240; Cavada 1992; CIRG, II, 124-125). Sus aguas sulfurosas termales (Oró 1995: 473) usadas por romanos ya debían ser conocidas por las poblaciones indígenas.

\section{Aquis Celenis-Tria ${ }^{8}$}

La calzada partía de Aquis Celenis (Cuntis) dirección noroeste por Pereira, Calvos, Casaldrago, Campo, Outeriño, Valga donde apareció una inscripción probablemente funeraria $(C I R G, \Pi, 123)$, Redondo, Cagaño, Paraíso y Puente Cesures. Este tramo será utilizado por el camino medieval que de Caldas de Reyes se dirigía a Santiago por Pontecesures (Ferreira 1988: 115), localidad en la que han hallado entre los restos arqueológicos, un tesorillo con numismas que abarcan desde la República hasta el siglo IV, inscripciones y ánforas que parecen indicar la posible existencia de un puerto fluvial (Piñeiro 1972: 16-32; Caamaño 1979: 84; Centeno 1987: 67; Naveiro 1991: 240, 248, 254; CIRG, II, 98-103; Sáez 2001a: 62; id. 2001b: 261-262).

En cuanto al paso del Ulla, aunque Ferreira Priegue (1988: 115) propone que se cruzaba por "el importante puente romano, que ya menciona Al-Idrisi en su descripción del camino" y en la actualidad aun se conserva el puente medieval (Alvarado 1989: 394). Sin embargo la existencia de un puerto en época medieval ${ }^{9}$ próximo al puente por donde no podían subir los buques de alto bordo nos alerta sobre el inconveniente que resulta para navegación la construcción de dicha obra con lo cual pensamos que la travesía se hacía en barca.

Tras cruzar el río, la calzada próxima a Lestrobe ${ }^{10}$ (Carré 1929: 789) se dirige por Padrón donde procede un miliario del emperador Graciano (CIL, II, Sup., 6232), Pedreira, Matanza y Arretén detrás de la iglesia de Iria " hasta Tria (Iria Flavia), con restos de cerámica común, terra sigillata, monedas e inscripciones (Chamoso 1972-74; Tranoy 1981: 57-58; Naveiro 1991: 236-248, 254, 258; CIRG, I, 12-18.21).

8. Hojas 152 y 120. Escala 1:50.000. Servicio Geográfico del Ejército.

9. 1194: Venta de casa y heredad en el fondo de la villa de Padrón. "sub ipsa congostra que venit de Portu Plano ad ruam inter eandem domun et domun manasterii de Armentaria” (ACS Tumbo Cl. XCIX vo). 1440: Apeo en Meroño [Rocha] Agro do Cavaleiro: "camiño foreiro que baja por el porto do Confurco; revoltas de Grovas, junto al río. Camino foreiro que pasa por el Porto de Grovas que está contra Sogil" (ACS Tumbo Iria, fol $75 \mathrm{v}^{\circ}$ ).

10. Aparecieron ladrillos, tégulas y fragmento de conducción de agua de cerámica.

11. 1223: Sobre la permuta de unos terrenos. "in circuitu Sancte Marie de Yria (...) quomodo dividunt ipsi agri ab inferiori parte de sub ecclesie per viam publicam quam dicitir ducit de Petrono ad Sanctum Jacobum [la calzada], et a superiori parte de super eccesia per viam publicam quam dicitur de ponte de Cesuris ad Sanctum Jacobum, et nominatim per agra de Olivaria que dividitur versus meridiem ab agro monasterii de Lampay et recte descendit ad viam piblicam quam ducit de Petrono ad Sanctum Jacobum et que iungitur Burgo de Petrono, et versus septentrione terminatur per vineam canonicorum de Yria, que plantata est iuxta ausidiam Sancte Marie de Yria, que vinea terminaturversus arietem per anticum caminum de Cesuris". (ACS Tumbillo, fol. 66.) 


\section{Tria-Assegonia ${ }^{12}$}

Desde Tria (Iria Flavia) parte hacia Roucón, montes Miranela y Lapido con restos de una antigua calzada (López 1898: 263). Continúa por Grela Chan, Regoute, Espasande y Santa María de Teo (López 1898: 263), vigilada por los castros de Valiñas, Lucí, monte do Castro y Rarís (Rey 1984: 114). Sigue por Vilanova, Seoane, Casal, Devesa, Noenlles y Procelas. Guardada por los castros do Coto y de O Croto (Varios 1987: 124-125) discurre por Cibrán, Quintans, cruza el río Zaramo por el puente de Busacos (Alvarado 1989: 338) y alcanza Aixón (Sergude, Boqueixón) o Assegonia, donde se constata presencia de una villa, un posible hypocaustum y un miliario de Calígula (CIL, II, Sup., 6233; Gorges 1979: 253; TIR K-29 1991: 20).

\section{Assegonia-Brevis $^{13}$}

La ruta parte de Assegonia (Aixón, Boqueixón) rumbo noreste hacia Mareque, Gidáns y Corneda, próxima a los castros da Moura, Barreiros y Prevediños (Rey 1984: 116). Prosigue por Noayo, Castro, la ermita de San Sebastián, Bravos, Mourelos y Touro, flanqueada por los asentamientos castreños de A Roda y da Copa (Rey 1984: 116).

Asciende en suaves zig-zags dirección Barral, Bentín, Oca, ermita de Santa Isabel junto al castro situado en Monte Cornado (Rey 1984: 67), Corredoiras, Pantiñobre al norte del asentamiento de Os Castros (Rey 1984: 67), y así avanzar próxima al camino por el que viajará el vino del Ribeiro de Avia y Miño hacia La Coruña (Ferreira 1988: 126) que venía de atravesar el Ulla por Tronceda y Branzá ${ }^{14}$.

En Pousada reanuda la marcha hacia Fondevilla, Vilar y Coto del Torrente entre los castros de Pastoriza la Vieja (Lema) al norte y el de Maroxo al sur (Rey 1984: 67). Continúa por monte Martelo e Iglesia población próxima a los castros de A Roda (S. Pedro de Villantine) y Boente (Santiago de Boente) (Rey 1984: 67). Alcanza Melide o Brevis por Cimadevila, Reboredo, Montoutiño y Catasol, escoltada por los poblados castreños de San Julián Monte, San Román, Varelas, Barreiro, Campos y Liñares al septentrión, y Visantoña, Belmil, Novela, Serantes y Moldes al sur (Álvarez 1906-1907: 278-279).

En Melide (Brevis) está documentado la presencia de restos constructivos y hallazgos monetarios de época de Augusto (Cavada 1973-1974: 184; Centeno 1987: 139), además de los castros O Castelo, Meire, Codesal, Torre dos Mouros, Campos y Apeancos (Naveiro 1991: 111 nota 119) en sus alrededores.

\section{Brevis-Marcie ${ }^{15}$}

Desde Brevis (Melide) cruza el río Furelos por el puente del mismo nombre (Alvarado 1989: 95-98, 340) para dirigirse a Leboreiro después de atravesar el arroyo Seco (Alvarado 1989:340). Entra en la región lucense por Cornija dirección Campanilla sobre una superficie donde la ausencia de fuertes pendientes, 400-600 m., será la tónica general hasta Lugo. Tras salvar el Rego de Vilar se encamina por Vilacendoy, Andemil, Sambreixo, Ulloa y Curbián donde se descubrió un ara votiva dedicada a Bandua Bolecco (IRL, 56) que podría guardar relación con posibles fuentes saludables (Diez 1987: 314; Oró 1995: 730). A través

12. Hojas 120 y 121. Escala 1:50.000. Servicio Geográfico del Ejército.

13. Hojas 121, 95 y 96. Escala 1:50.000. Servicio Geográfico del Ejército.

14. "por la villa que se llama de Agilar e por el castro de Santa Leocadia [de Branzá], e por el marco que es sobre Tronceda, e de ay por la fuente sagrada [Fuentesanta] e por el río de aquella fuente que va a dar en la Ulla, e por la fuente de las arenas et por el marco Felis e por el castro de Usiame [Duxame], e dalli va topar sobre la puente..." (AHD Stgo. S. Martín Pinario, carp. 57).

15. Hojas 96 y 97. Escala 1:50.000. Servicio Geográfico del Ejército. 
de un camino que cruza la parroquia de Carballal a Palas de Rey avanza por Fontecuberta, Moreira cerca del castro de Domiz, Fonte de Uz, Villamourel, Camouco, Pereirón y Ribeira. Prosigue por Xende atravesando el arroyo de Vilela dirección Marciae/Ponte Nartiae Burgo de Negral (Pacio, Friol, Lugo) localidad próxima al río del mismo nombre, por donde discurría uno de los caminos de peregrinación a Santiago (Vázquez 1949: II, 501).

\section{Marcie-Luco Augusti ${ }^{16}$}

Saliendo de Burgo de Negral (Marcie o Ponte Nartiae) la vía continúa hacia San Román de Retorta donde se halló un miliario de Calígula (IRL, 93), Villarreal, San Pedro de Mera por la Casa de Rúa que puede aludir a la rúa primitiva (Ares 1993: 24), Mourentaos y San Miguel de Bacurín, con un castro en sus proximidades (Ares 1967-68: 188); sigue por Prógalos cerca del asentamiento castreño (Ares 1967-68: 187) y San Martín de Poutomillos junto a otro recinto de similares características (Ares 1967-68: 186). Existe en este punto un desvío hacia el norte que lleva a Santa Eulalia de Bóveda, localidad donde se descubrió un edificio abovedado con un estanque que para Oró (1993: 352-353) "se trataba de una ninfeo de época romana, como corroboran también una serie de restos hallados por los alrededores (tégulas y trazos cerámicos de terra sigillata). Ninfeo puesto bajo la advocación de unas Ninfas quienes los enfermos que allí acudían en busca de las aguas pedirían su curación. Aguas que, como hemos demostraron análisis efectuados, resultaban indicadas para combatir el reumatismo, entre otras enfermedades", a lo que debemos añadir la presencia de restos de mosaico, pinturas, relieves y dos epígrafes (Acuña 1973: 45-47; Abad 1979: 917-922; IRL, 74, 88).

Desde Poutomillos avanza por Caraloces, San Vicente del Burgo, Carrigueiros, próxima al castro de Seara-Rabordaos, Famela, Villaestevez y Santiago de Piugos donde apareció una inscripción funeraria de Lucius Valerius Severus (IRL, 76). Continúa por Pena, Mesón del Gallo y Pontegaos localidad en la que se descubrió una nueva inscripción (IRL, 77).

Cruza el Minus flumen sobre el puente romano, cuya fecha de construcción se desconoce aunque se podría encuadrar entre el s. I comienzos del II. La obra actual es fruto de múltiples reparaciones y ampliaciones, de hecho hasta el siglo XVIII tuvo siete vanos añadiéndose un octavo en la margen izquierda, los arcos son ojivales y de medio punto siendo más antiguos los de la margen derecha, los tajamares son apuntados a dos aguas (Alvarado 1989: 89-92). Desde el puente sube en zig-zag hasta alcanzar la puerta Miñá en Lucus Augusti, cuyo "sistema constructivo nos da la pauta de todas las puertas romanas que tuvo la fortificación" (Arias 1972: 44).

\section{Luco Augusti-Timalino ${ }^{17}$}

El camino a Timalino salía por la Puerta de San Pedro o Puerta Toledana ${ }^{18}$ hacia Santa María de Bóveda, San Lorenzo de Recimil y Arxemil (Arias 1976: 103) donde se hallaron dos miliarios, uno de Adriano y otro anepígrafo $(I R L, 94,97)$, y en cuyas inmediaciones se detectaron los castros de Tras da Zorra, Racimil y el castro de Novas (Rielo 1980: III, 383).

16. Hojas 97 y 72. Escala 1:50.000. Servicio Geográfico del Ejército.

17. Hojas 72 y 98 . Escala 1:50.000. Servicio Geográfico del Ejército.

18. 1174: Venta de propiedades de Lugo "circa viam qua itur de eclesie sancte Marie ad burgorum novum et ad Toletanam portam inter ipsam viam et muros civitatis" (AHN. C. Lugo 1325-F/15 bis). 
Cruza el río Chamoso por el viaducto de un solo arco con rasante apuntada conocido por puente de Galiñeiros (Alvarado 1989: 352), prosigue por Piedrafita (Arias 1976: 105), Bergazo, Rioseco, Pedradereita (Arias 1976: 103) y Val. Rodea el Monte das Medorras y asciende por Iglesia, Vilarello con restos de mámoas (Rielo 1980: VI, 372), Palacio, Seoane, Cruceiro, Airexe, Recesende y Santa Marta.

Conforme nos acercamos a Basile, desciende hasta Senra flanqueada por los castros de Ferreiros y el romanizado de Pousada (Arias 1976: 105), supera el río Neira por su puente medieval ${ }^{19}$ y entra en Baralla la antigua Timalino, cuya importancia minera queda confirmada por sus explotaciones auríferas, además de las de Constantín y Neira de Xusa (Domergue 1990: 41, 200) preservadas por los castros de Pousada, Quinta y Vilartelín, junto al hallazgo de inscripciones en Santiago de Aranza (IRL, 59, 73).

\section{Timalino-Ponte Neviae ${ }^{20}$}

La vía que parte de Timalino (Baralla), circula por Constantín ${ }^{21}$ Monte do Base, Gondian ${ }^{22}$, Liñares y Acebo, controlada por los castros de Sigirey, Lejo, Pol y Vilouta (Rielo 1980: III, 396; IV, 49-50; V, 181). En Acebo baja en zig-zag hasta Cerezal, continúa por Carballín y Castelo hasta Becerreá con vestigios de un antiguo castro. Prosigue hacia Venta de Cruzul, atraviesa el río Narón, alcanza la cima en Adrao y llega a Chao da Vila tras dejar a su izquierda el conjunto castreño de Guillen (Rielo 1980: III, 224). Supera el Monte Valderroxo y desciende hasta Los Nogales o Ponte Neviae donde se constató la presencia de monedas de Augusto, Constantino I y Crispo, además de edificaciones castreñas en sus alrededores (Fariña 1972: 113; Rielo 1980: IV, 370; Centeno 1987: 143).

\section{Ponte Neviae-Uttaris ${ }^{23}$}

La vía sale de Ponte Neviae (Los Nogales) hacia Espariz, Doncos y Noceda, por donde Lemaur al diseñar el Camino Real de Galicia que enlazaba La Coruña y Madrid, cuyas obras se iniciaron en 1763, utiliza la primitiva calzada romana que unía Asturica (Astorga) con Luco Augusti (Lugo) y Brigantium (La Coruña) recogida en el Itinerario de Antonino. Carlos Lemaur conocedor de la ruta (García-Fuentes 1987: 27) ${ }^{24}$, presenta dicho trayecto en base a razones de carácter histórico (Nárdiz 1992: 227), y en los sistemas constructivos planteados por Fernández Mesa (1775) y Gautier (1750) que ven en el modelo romano el más adecuado para la ejecución de caminos.

Así el Camino Real mantiene prácticamente la misma dirección que la antigua vía romana hasta Piedrafita del Cebrero, para seguir como propone Rabanal Alonso (1988: 28) entre El Castro en cuyas inmediaciones

19. 1326: Ventas de unas heredades "dello vao de Ryu Seco a a suso et en curro e en Dodies... como se departe porlos terminos da serra d'Açevedo e da ponte de Neyra e de San Pero, e he su sino de Santa María de Cascallas" (AHN Penamayor, 1222/16). 1348: "Yten mando o moyño que fis na Neyra, çerca de dita povoa cabo da ponte de Sancto Estevoo" (Ibid. 1225/8).

20. Hojas 98, 99 y 125. Escala 1:50.000. Servicio Geográfico del Ejército.

21. 1179: Venta de una heredad entre Baralla y Constantin "loco nominato Aer de Abadesa... per terminum de ipsa via antiqua" (AHN O. Militares, S. Juan, leg. 89/8).

22. 1332: Donación de la heredad de Lodeiros, en Constantin "vay firir na outra mamoa de fondo como vay pola carreyra da serra que vay para Gondian" (AHN Penamayor 1223/9).

23. Hoja 125. Escala 1:50.000. Servicio Geográfico del Ejército.

24. Afirma Lemaur que "conocía, por haberla andado, la antigua vía militar que va desde Astorga a León, Sahagún, Carrión y Burgos. Otra que salía de Astorga hacia Zamora pasando por el Esla y que iba después a Salamanca y Mérida. Estos dos unían en Astorga y tenían su continuación hasta Lugo, Brigantium y Braga". 
aparecieron restos arqueológicos (Gómez 1925: 5) y Chao de Ceiras, Las Lamas, San Tirso junto a un antiguo emplazamiento en el lugar llamado El Auteiro (Mañanes 1988: 116) y Ruitelan donde se cumplen las 20 m.p. o los $30 \mathrm{~km}$. que hay entre Ponte Neviae y Uttaris.

\section{VALORACIÓN DE LOS ESTUDIOS PRECEDENTES}

En lo referente a las hipótesis formuladas, observamos en el trabajo de Barros Silvelo (1875: 163-165) que los trayectos entre Tude (Tui), Burbida (Borbén) y Turoqua (Tourón), y entre Luco Augusti y Timalino (Bertelín de Neira), aunque cumplen las distancias marcadas por el Itinerario, en base a los $1.480 \mathrm{~m}$. como valor métrico de la milla romana, se comprueba que dichos trazados no obedecen al característico esquema romano, dirigidos por las divisorias de agua (Saavedra 1963: 85), sobre terrenos elevados, a nivel constante y al abrigo del viento, además de evitar probables emboscadas (Chevalier 1972: 128). La elección de estos recorridos viene determinada tanto por razones defensivas (dominio del territorio ante posibles ataques), como por causas naturales entre las que cabe destacar durante los períodos de lluvia el aumento de caudal en los ríos, arroyos, etc. y la constante caída de agua por las pendientes deteriorando en ambos casos la calzada (Sáez 1998: 188). En cuanto a la relación Burbida/Borbén, Toruqua/Tourón y Timalino/Bertelín de Neira no parece muy segura ante la falta de restos arqueológicos localizados, hasta el momento, en dichas localidades.

Aunque en su estudio se aprecia que determinados tramos se ajustan a las distancias señaladas por la fuente, sirvan de ejemplo los mencionados y el trayecto de Aquis Celenis (Caldas de Reyes) a Tria (Iria) cuyo recorrido no se corresponde con el recogido por el Itinerario de Antonino sino con parte de un tramo viario que unía Ad Duos Pontes (Pontevedra) con Iria (Iria Flavia) (Sáez 2000: 244-245); sin embargo comprobamos que no sucede lo mismo en todo el trazado, y así lo reflejan los tramos entre Turoqua (Tourón) y Aquis Celenis (Caldas de Reyes), o entre Tria (Iria) y Assegonia (Oines) donde las 13 millas (20 km.) recogidas por Antonino se disparan a unos $40 \mathrm{~km}$., junto al recorrido entre Assegonia (Oines) y Brevis (San Salvador de Abeancos) en el que las 22 millas ( $33 \mathrm{~km}$.) indicadas por el Itinerario se reducen a unos $22-25 \mathrm{~km}$, sin olvidar el trayecto desde Macie (Marzán) hasta Luco Augusti.

En el estudio presentado por Blázquez (1923: 10-18) se contempla que entre Tude (Tui), Burbida (Borbén), Turoqua (Tourón) y Aquis Celenis (Caldas de Cuntis), aunque se cumplen las distancias formuladas por el Itinerario, y la ubicación de Aquis Celenis en Cuntis coincide con nuestra hipótesis, el trazado no obedece al patrón típico romano. Asimismo no parece muy satisfactoria la idea del cambio del valor métrico de la milla romana por $1.666 \mathrm{~m}$. desde Pria (Padrón) a Luco Augusti, al igual que el excesivo cruce de arroyos con su correspondiente construcción de puentes entre Assegonia (Aixón) y Brevis (proximidades del río Iso), si tenemos en cuenta que las vías romanas "se hicieron con muy corto trabajo de explanación, dirigiéndose por las divisorias de último orden o por los más suaves descensos de las colinas, por las altas mesetas o por las llanuras despejadas, economizando al mismo tiempo las obras que para el paso de las aguas exigen nuestros trazados en ladera" (Saavedra 1863: 85).

Respecto al trayecto Luco Augusti, Timalino (Villartelín, Baralla), Ponte Neviae (Gatín) y Uttaris (Vega de Valcárcel), no compartimos el esquema propuesto ya que no solo no se ajustan las distancias entre las diferentes mansiones propuestas, sino que el propio trazado no se ciñe al característico esquema viario romano, como pone de manifiesto parte del recorrido entre Ponte Neviae (Gatín ) y Uttaris (Vega de Valcárcel) donde las-localidádes comprendidas entre Gatín y Mosteiro se sitúan en la orilla del río Cervantes sobre la cota de la corriente, mientras que el trazado romano iría a mayor altura.

La idea de Ponte Neviae/Gatín en base a un puente sobre el río Navia de un solo arco que presenta señales de sucesivas reparaciones y en el que puede apreciarse la primera fábrica de época romana, junto a la presencia 
de restos de edificación romana, un miliario hoy día desaparecido, y la denominación del río Navia a partir del puente citado, lo cual impide la colocación del Ponte Naviae del Itinerario en Nogales (Blázquez 1923: 10-11), resulta atrayente. Sin embargo por dicha población no pasaba la vía 19 del Itinerario Antonio, sino la que unía la mansión recogida en el Anónimo de Ravena Ponte Abei ${ }^{25}$ (Santiso, Fonsagrada, Lugo) y Uttaris (Ruitelan) a través de Navia de Suarna (Sáez 1998: 186-187). Respecto a la denominación del Navia a partir de Gantín no es un dato significativo, primero porque en Los Nogales se le conoce con este nombre y segundo porque tanto el Rego de San Andrés, como el Bollés y el Boullón, arroyos que vierten sus aguas en el Navia a la altura de Los Nogales pudieron recibir tal designación en época romana dada su proximidad.

El trabajo de Monteagudo (1951: 202-215) aunque resulta de sumo interés, estimamos que el tramo Tude (Tui), Turoqua (Sajamonde) y Tria (Padrón), a pesar de omitir la mansión de Burbida, corresponde a la vía que unía Tude (Tui) con Tria (Iria Flavia) a través de Vico Spacorum (Vigo) y Ad Duos Pontes (Pontevedra) (Sáez 2000: 239-240, 244-245), y no con la vía en cuestión. Respecto al resto del estudio comprobamos que las distancias no se ajustan a las determinadas por el Itinerario.

Desde Tude (Tui) a Aquis Celenis (Cuntis), Estefanía (1960: 51-53) mantiene la hipótesis formulada por Blázquez con todo lo que ello implica. A partir de Aquis Celenis (Cuntis) observamos que hasta Tria (Sergude, Boqueixón) supera sin mucha dificultad las $12 \mathrm{~m}$.p. (18 km.) que marca el Itinerario, y no ofrece ninguna solución respecto a la ubicación de Assegonia en las proximidades de Arzúa. Sin embargo, aunque el tramo Assegonia (proximidades de Arzúa), Brevis (Furelos, Melide) y Marcie (Marzán) parece correcto a tenor de las distancias señaladas por el Antonino, no sucede lo mismo entre última mansión y Luco Augusti, al igual que entre esta, Timalino (Campo de Árbol) y Ponte Neviae (Gatín). Asimismo tras examinar el itinerario propuesto, comprobamos que no mantiene las disposiciones propias del trazado romano.

Aunque nuestro hipotético trazado coincide con el propuesto por Ares Vázquez (1977-78: 3-7) entre Marcie y Luco Augusti, no sucede lo mismo a la hora de determinar la situación de la mansión viaria. Mientras Ares propugna la ubicación de Ponte Martiae en Ponte Ferreira en base a las cuatro leguas que según Madoz existen entre Lugo y Ferreira de $\mathrm{Negral}^{26}$, y tras determinar la probabilidad del cómputo de millas desde el puente de Lugo al de Ferreira, nosotros estimamos que dicho cómputo se realizaría desde la mansión hasta la misma capital del Convento.

Los recorridos presentados por Arias (1987: 14-26.80; 1988: 15-18; 1989: 7-10) en sus distintas publicaciones resultan interesantes y en algunos casos aunque coinciden con trazados romanos, observamos que entre las mansiones propuestas no concuerdan las distancias con las establecidas por el Itinerario de Antonino.

En cuanto a la teoría planteada por Peña Santos (1990-91: 217-243) de dibujar la ruta a través de la Depresión Meridiana desde Tui (Tude) por Vilar de Enfesta (Burbida), Pontevedra (Turoqua), Caldas de Reyes (Aquis Celenis) e Iria Flavia (Iria) hemos de señalar que se trata de una vía romana pero no la que recoge el Itinerario de Antonino, sino la que desde Tude (Tui) continúa por Vico Spacorum (Vigo) y Ad Duos Pontes (Pontevedra) hasta Tria (Iria Flavia) (Sáez 2000: 239-240 y 244-245). Respecto al tramo Turoqua (Pontevedra) y Aquis Celenis (Caldas de Reyes), donde la distancia real entre ambas localidades supera en $15 \mathrm{~km}$. la medida propuesta por el Itinerario, aunque la solución formulada por el autor mediante la adición involuntaria de una $\mathrm{X}$ a la cifra que marca el recorrido resulta sugerente, nos parece un poco forzada a pesar de los "errores frecuentes" del Antonino.

Tras lo expuesto queremos expresar nuestra más sincera gratitud a todos los autores a quienes hemos hecho referencia, sin los cuales hubiera sido imposible realizar este estudio. Igualmente queremos agradecer a todas aquellas personas que han nos han apoyado y ayudado en todo momento.

25. Ravenn. 321, 2: Ponte Abei

26. Aproximadamente a $30 \mathrm{~km}$. de Lugo. 


\section{BIBLIOGRAFÍA}

ABAD CASAL, L. (1979): “Aportación al estudio de Sta. Eulalia de Bóveda" XV CNA, Lugo 1977, Zaragoza. ACUÑA CASTROVIEJO, F. (1973): "Mosaicos romanos de Hispania Citerior II. Conventus Lucensis" StArch., 24.

ACUÑA FERNÁNDEZ, P. y GARCÍA ALÉN, A. (1975): "Nuevo hallazgo en Taboexa (Pontevedra)", Museo de Pontevedra XXIX.

ALVARADO, S. et alii (1989), Pontes históricas de Galicia, Santiago de Compostela.

ÁLVAREZ CARBALLIDO, E. (1906-1907): "Descripción y mapa prehistórico de la villa de Mellid y sus alrededores", BRAG I.

ÁLVAREZNÚÑ̃Z, A. (1991): "Castro de Penalba (Campo Lameiro, Pontevedra)" Arqueoloxía/Informes. Campaña 1988, 2.

ARES VÁZQUEZ, N. (1967-68): "Castros en torno a Sta. Eulalia de Bóveda", $B C P M L$, VIII, nº 67-70.

_- (1977-78): "La mansión romana de Ponte Martiae", BCPML X: 3-7. (1993): "El camino primitivo de Santiago: De Lugo a Mellid", Lucensia 6.

ARIAS BONET, G., (1987): "Los caminos del duumviro Lépidus y otras vías romanas. II. Segunda tableta: A) Vía de Lucus a Iria", Repertorio de caminos de la Hispania romana: 14-26.

- (1987): "Nota recapitulativa sobre la situación de Iria", Repertorio de caminos de la Hispania romana 80. (1988): "En torno a Aquis Celenis y algo más. Diálogo epistolar con don Hipólito de Sa Bravo", ME 18: 15-18.

(1989): "La vía A 19 a la luz del miliario de O Burgo", ME 20: 7-10.

ARIAS VILAS, F. (1972): "Las murallas romanas de Lugo", StArch 14. (1976): "Dous miliarios do tramo viario Lucus-Timalino", BolAur VI.

BARROS SILVELO, R. (1875): Antigüedades de Galicia, La Coruña.

BLÁZQUEZ Y JIMÉNEZ, A. (1923): "Vías de Sigüenza a Zaragoza, de Alhambra a Zaragoza, del Bierzo a Lugo, de Lugo a Betanzos, de Betanzos a Padrón, de Tuy a Padrón y de Padrón a Lugo", MJSE 52.

CAAMAÑO GESTO, J. M. (1979): "Marcas de alfarero en cerámica romana encontradas en Galicia", Gallaecia 5.

CAVADA NIETO, M. (1973-74): "Recientes hallazgos monetarios en Galicia", Numisma XXIII-XXIV. (1992): "Monedas romanas en la ceca Hispana halladas en Galicia", Gallaecia 13.

CARRÉ ALDAO, (1929): Coruña, Geografía general de Galicia, dirigida por Carreras Candi.

CEÁN BERMÚDEZ, J.A. (1892): Antigüedades romanas que hay en España en especial las pertenecientes a las Bellas Artes. Madrid.

CENTENO, R.M.S. (1987): Circulaçao Monetária no noroeste de Hispânia ate 192, Anexos NVMMVS $\mathrm{n}^{\circ} 1$. Porto.

CHAMOSOLAMAS, M. (1972-1974): “Noticia sobre la importancia arqueológica de Iria-Flavia (Padrón-La Coruña)", AEspA: 125-130.

CHEVALIER, R. (1972): Les voies romaines. París.

CIRG I: PEREIRA MENAUT, G. (1991): Corpus de Inscripcións Romanas de Galicia. Tomo I Provincia de La Coruña dirigido por G. Pereira Menaut. Santiago.

CIRG II: BAÑOS RODRÍGUEZ, G. (1994): Corpus de Inscripcións Romanas de Galicia. Tomo II Provincia de Pontevedra dirigido por G. Pereira Menaut. Santiago.

CIL : HÜBNER, E. (1869 y 1892): Corpus Inscriptionum Latinarum. II y Suplementum, Berlín.

CRUZ CANTERO, J. (1986): Guía de balnearios.

DIEZ DE VELASCO, F. (1985): "Balnearios y dioses de las aguas termales en la Galicia romana", AEspA 58. (1987): Balnearios y divinidades de las aguas termales en la Península Ibérica en época romana, Madrid. 
DOMERGUE, C. (1990): Les mines de la Péninsule Ibérique dans l'antiquité romaine, Roma.

ESTEFANÍA ÁLVAREZ, M.D. (1960): "Vías romanas de Galicia", Zephyrus XI.

FARIÑA BUSTO, F. (1972): "Algunos aspectos de la circulación monetaria en Gallaecia durante el s. IV d.C.", I CNN. Zaragoza.

FERNÁNDEZ MESA, T.M. (1755): Tratado legal y político de caminos públicos y posadas, dividido en dos partes, la una en que se habla de los caminos y la otra, de las posadas así públicas como privadas; donde se incluye el Reglamento General de aquellas expedido en 23 de abril de 1720. Valencia.

FERREIRA PRIEGUE, E. (1988): "Los caminos medievales en Galicia", BolAur, Anexo 9. Orense.

FILGUEIRA VALVERDE, J. y GARCÍA ALÉN, A. (1954-1956): "La carta arqueológica de la provincia de Pontevedra", Museo de Pontevedra VIII.

FILGUEIRA VALVERDE, J. y GARCÍA ALÉN, A. (1959): “Adiciones a la carta arqueológica de la provincia de Pontevedra", Museo de Pontevedra VIII.

GARCÍA ROMERO, C. (1916a): "Memorias romanas de Cuntis", BRAG IX.

(1916b): "Memorias romanas de Cuntis II", BRAG X.

GARCÍA-FUENTES, M. (1987): El camino de acceso a Galicia en el siglo XVIII. La Coruña.

GAUTIER, H. (1750): Traité de la construction des chemins. París.

GÓMEZ MORENO, M. (1925): Catálogo Monumental de España. Provincia de León. Madrid.

GORGES, J.G. (1979): Les villas hispano-romaines. Inventaire et problématique archéologiques. París.

HIDALGOCUÑARRO, J.M. (1995): "Castro de Troña. Campaña 1983" Arqueoloxía/Informes. Campaña 1989, 3.

IRL: ARIAS, F. et alii (1979): Inscriptions romaines de la province de Lugo. París.

LÓPEZ FERREIRO, A. (1898): Historia de la Santa Iglesia de Santiago de Compostela I. Santiago de Compostela.

MADOZ, P. (1845): Diccionario geográfico-estadístico-histórico de España y sus posesiones de Ultramar, Madrid.

MAÑANES, T. (1988): Arqueología de la cuenca leonesa del río Sil (Laceana, Bierzo, Cabrera). Valladolid. MARTÍN SARMIENTO, Fr. (1975): Viaje a Galicia (1745). Pontevedra.

MONTEAGUDO GARCÍA, L. (1951): "Carta de La Coruña romana", Emérita XIX: 191-225.

NÁRDIZ ORTIZ, C. (1992): El territorio y los caminos en Galicia. Planos históricos de la red viaria. Madrid.

NAVEIRO LÓPEZ, J. (1991): El comercio antiguo en el noroeste peninsular. La Coruña.

PEÑA SANTOS, A. de la (1990-1991): "Consideraciones sobre las vías romanas de la provincia de Pontevedra", Castrelos III-IV: 225-226.

PIÑEIRO ARES, J. (1972): Historia de Pontecesures.

ORÓ FERNÁNDEZ, E. M.(1995): Aguas minero-medicinales y balnearios de la Hispania romana. Aspectos médicos, funcionales y religiosos, Universidad de Valencia Tesis Doctoral.

RABANAL ALONSO, M. A. (1988): Vias romanas de la provincia de León. León.

ROLDÁN HERVÁS, J.M. (1975): Itineraria Hispana. Valladolid.

REY CASTIÑEIRA, J. (1984): "Estudio y catalogación de castros de la provincia de La Coruña", Gallaecia 7/8.

RIELO CARBALLO, N. et alii (1980): Inventario artístico de Lugo y su provincia, dirigido por Valiñas San Pedro. Madrid.

SAAVEDRA, E. (1863): Discursos leídos ante la Real Academia de Historia en la recepción pública de D. Eduardo Saavedra el día 28 de diciembre de 1862, Madrid. 
SÁEZTABOADA, B. (1996): Las vías romanas en la provincia de Lugo, Memoria de Licenciatura. (Inédita). Sevilla.

(1998): "Elementos para el estudio de la caminería en la Galicia romana: La vía Lucus Augusti-Ponte Abei", Habis 29.

(2000): Vías 19 y 20: Trazado y función. Tesis Doctoral. (Inédita). Sevilla. (2001a): Las comunicaciones romanas en la provincia de A Coruña, A Coruña. (2001b): "El tramo marítimo de la vía 20 del Itinerario de Antonino", Gallaecia 20.

TIR : TABVLA IMPERII ROMANI (1991): Hoja K-29: Porto.

TRANOY, A. (1981): La Galice romaine. Recherches sur le nord-ouest de la Péninsule Ibérique dans l'Antiquité. París.

VALVERDE ÁLVAREZ, J. (1957): “Apuntes para una carta arqueológica de los valles del Tea" Museo de Pontevedra XI.

VV.AA. (1987): "Catalogación de yacimientos prerromanos del ayuntamiento de Santiago", Arqueoloxía/Investigación.

VÁZQUEZ de PARGA, L. et alii (1949): Las peregrinaciones a Santiago de Compostela. 


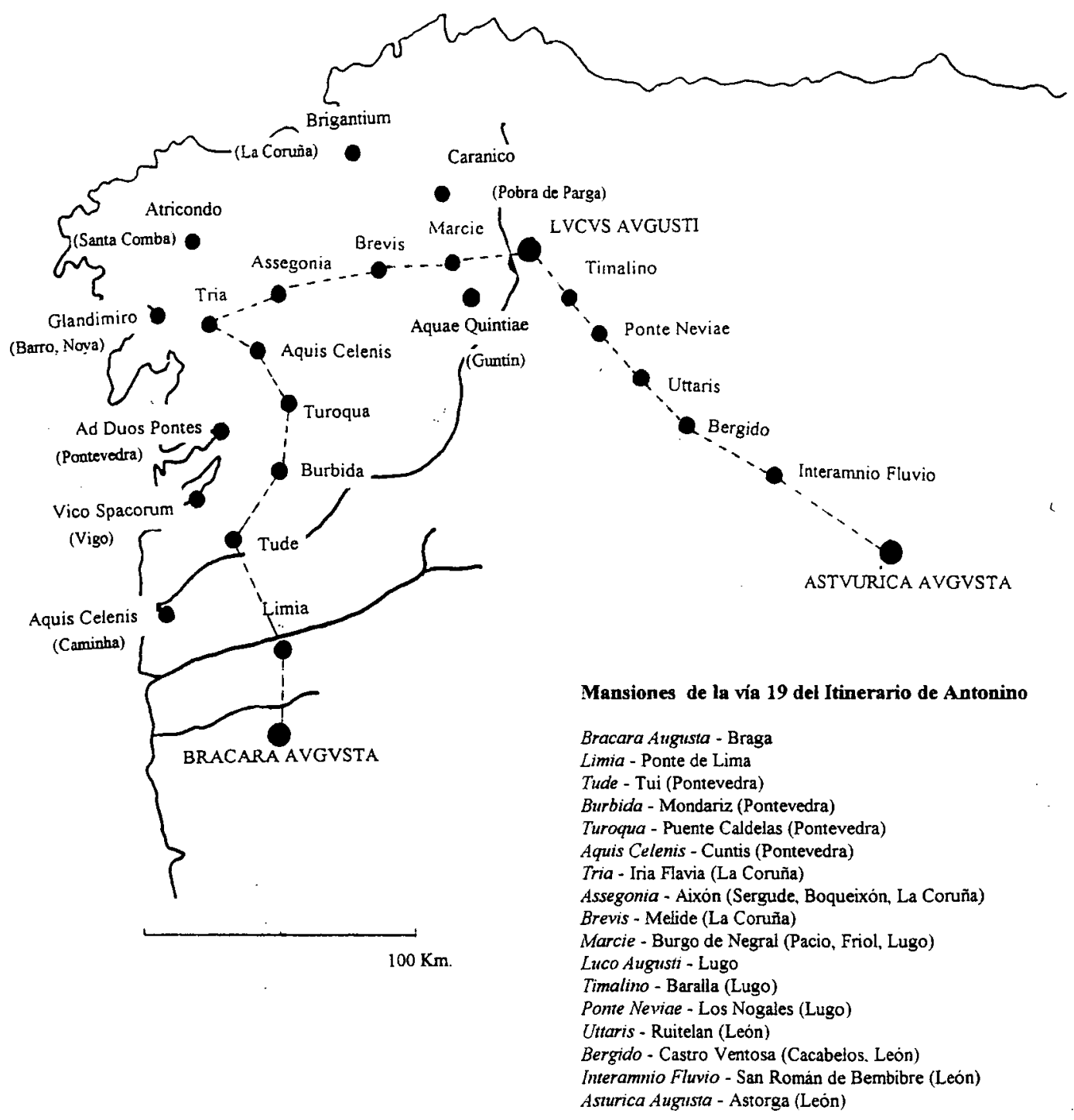

Fig. 1. Hipotético trazado de la vía 19 del Itinerario Antonino. 


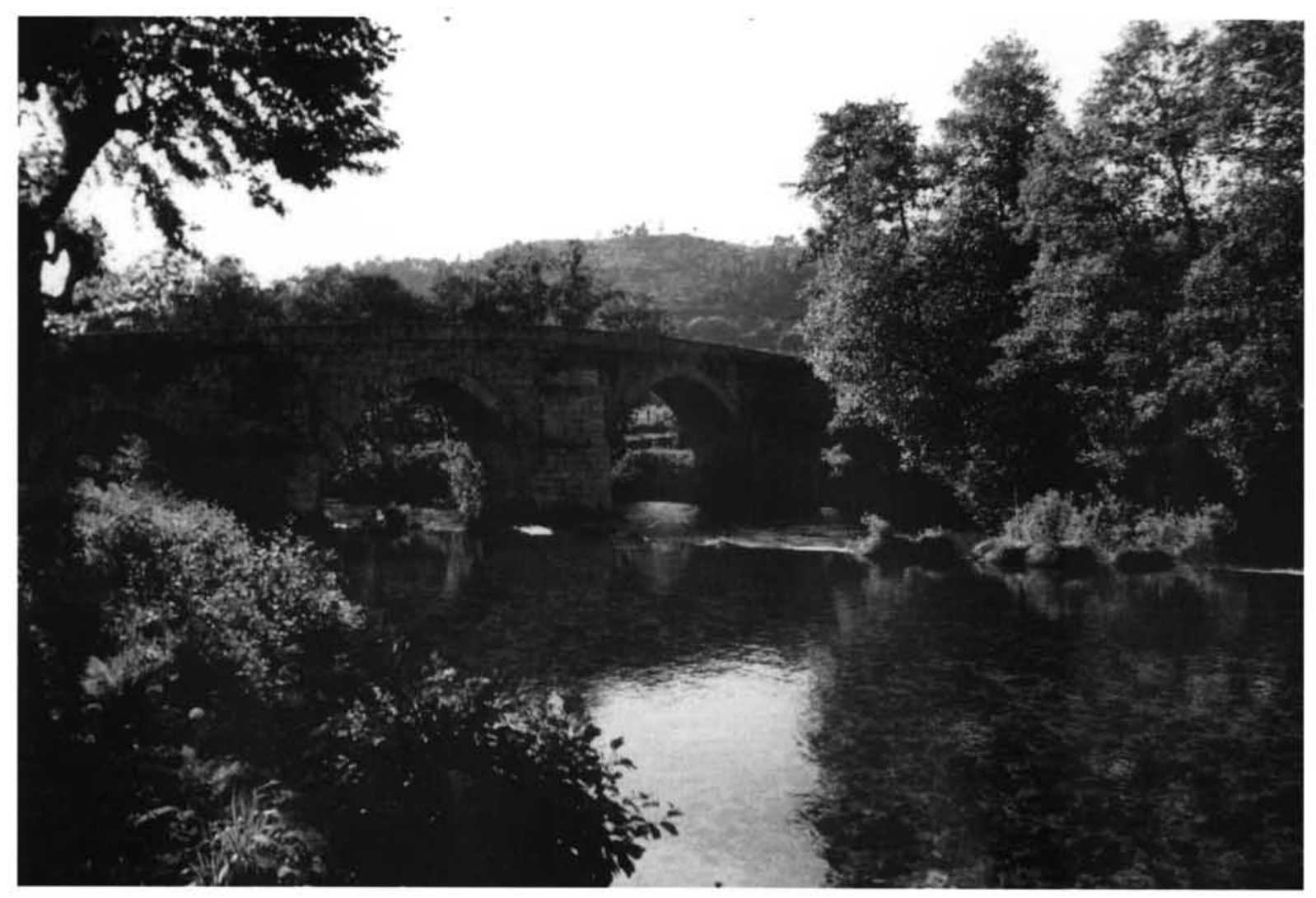

Lámina I. Burbida - Turoqua: Puente de Cernadela. (foto B. Sáez Taboada). 


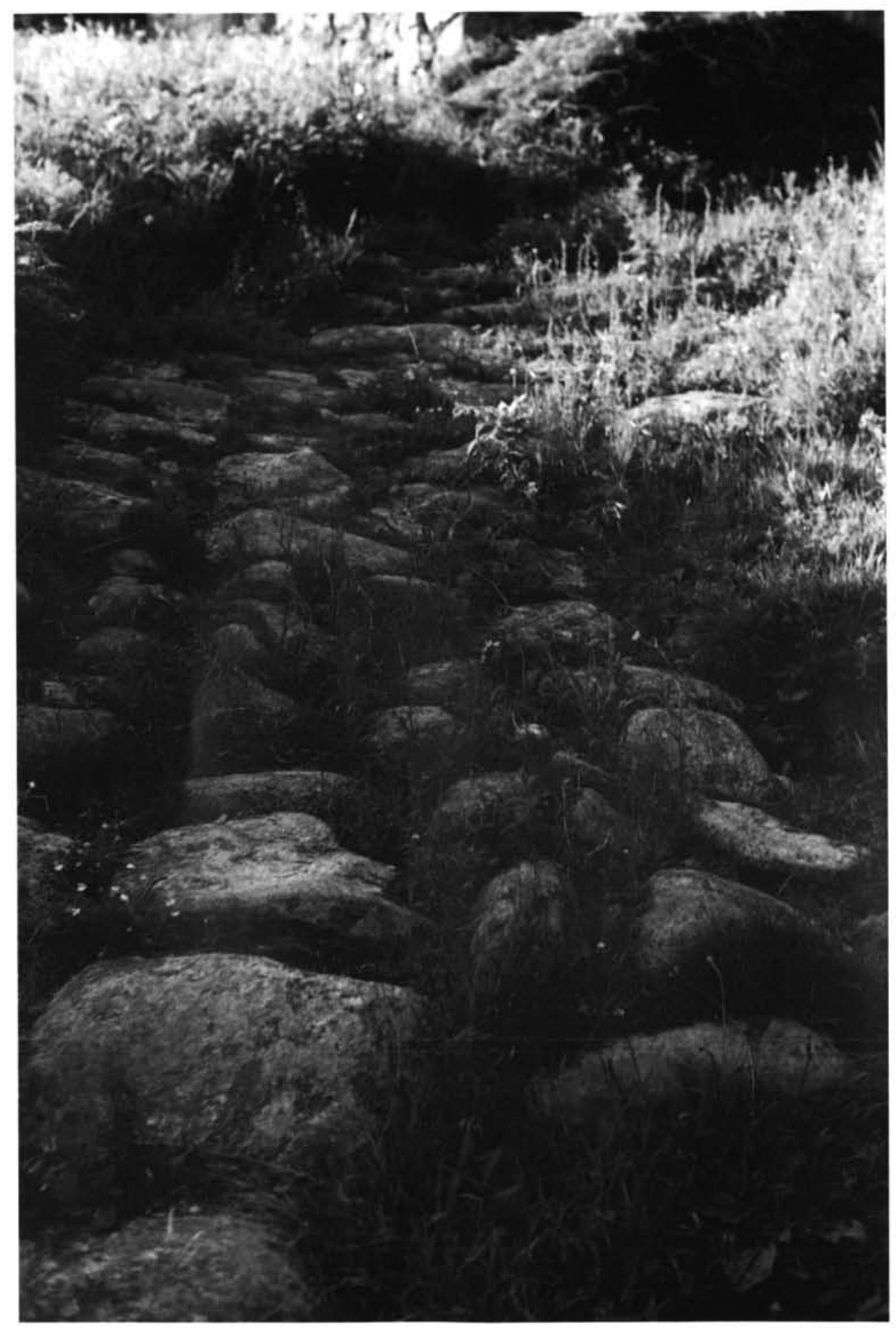

Lámina II. Burbida - Turoqua: Restos de calzada en A Rúa (foto B. Sáez Taboada). 


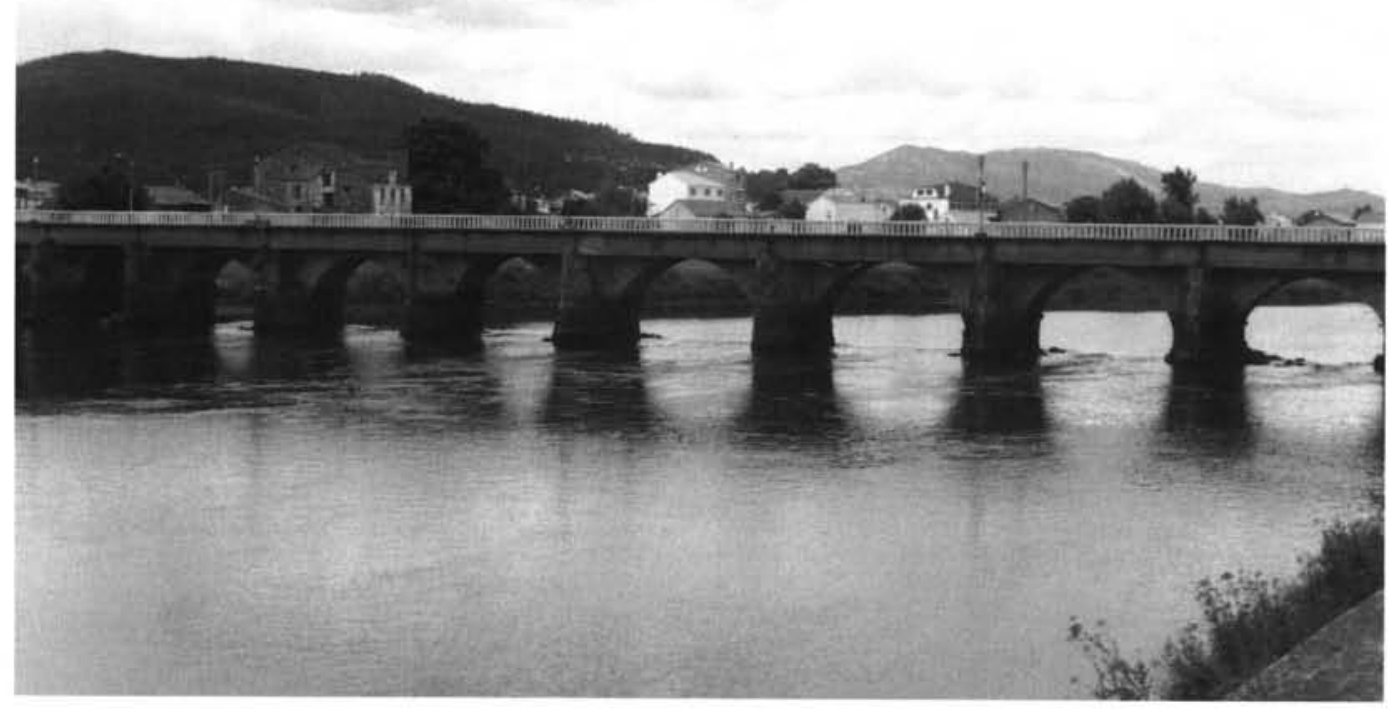

Lámina III. Aquis Celenis - Tria: Puente Cesures (foto B. Sáez Taboada).

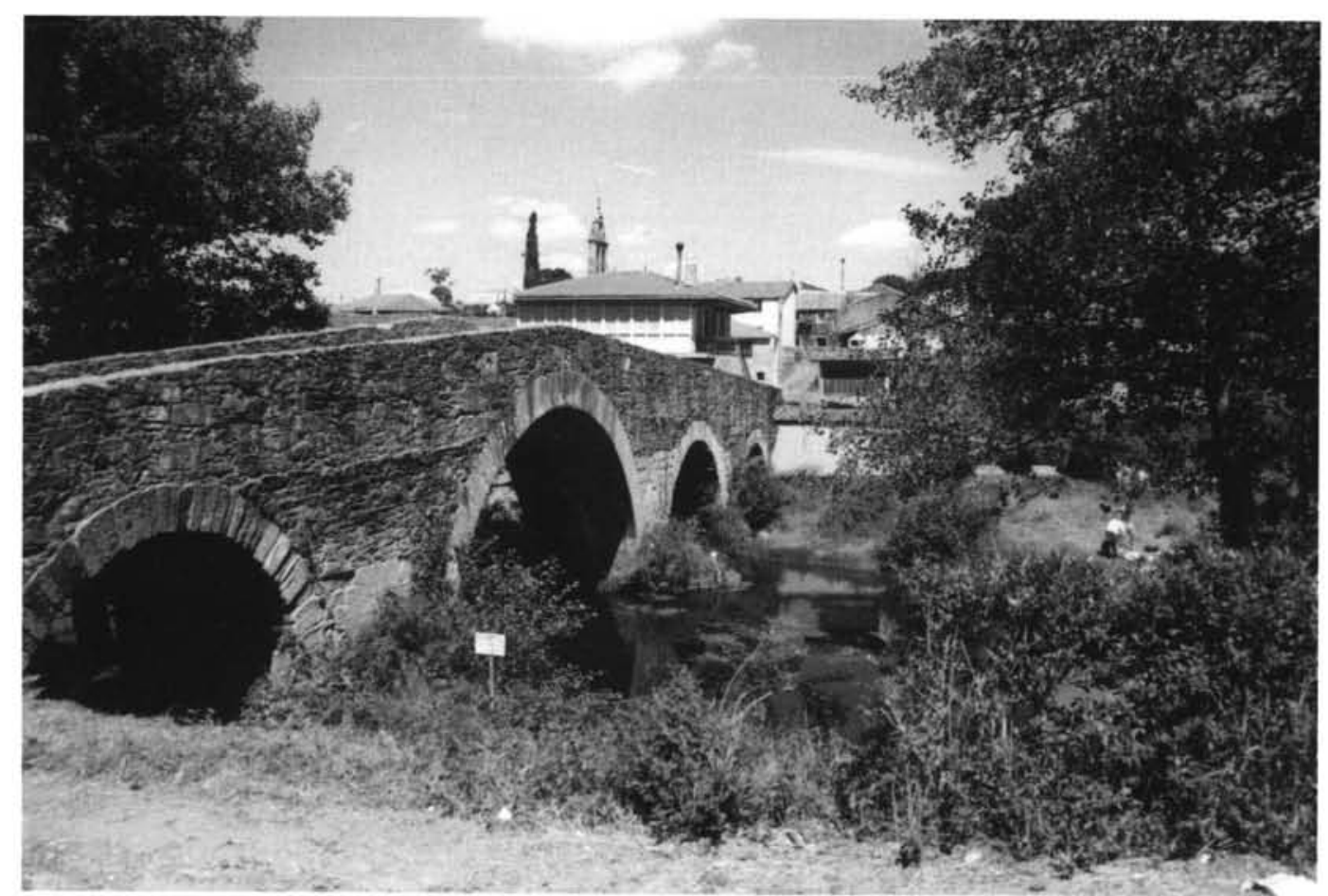

Lámina IV. Brevis - Marcie: Puente viejo de Furelos (foto B. Sáez Taboada). 


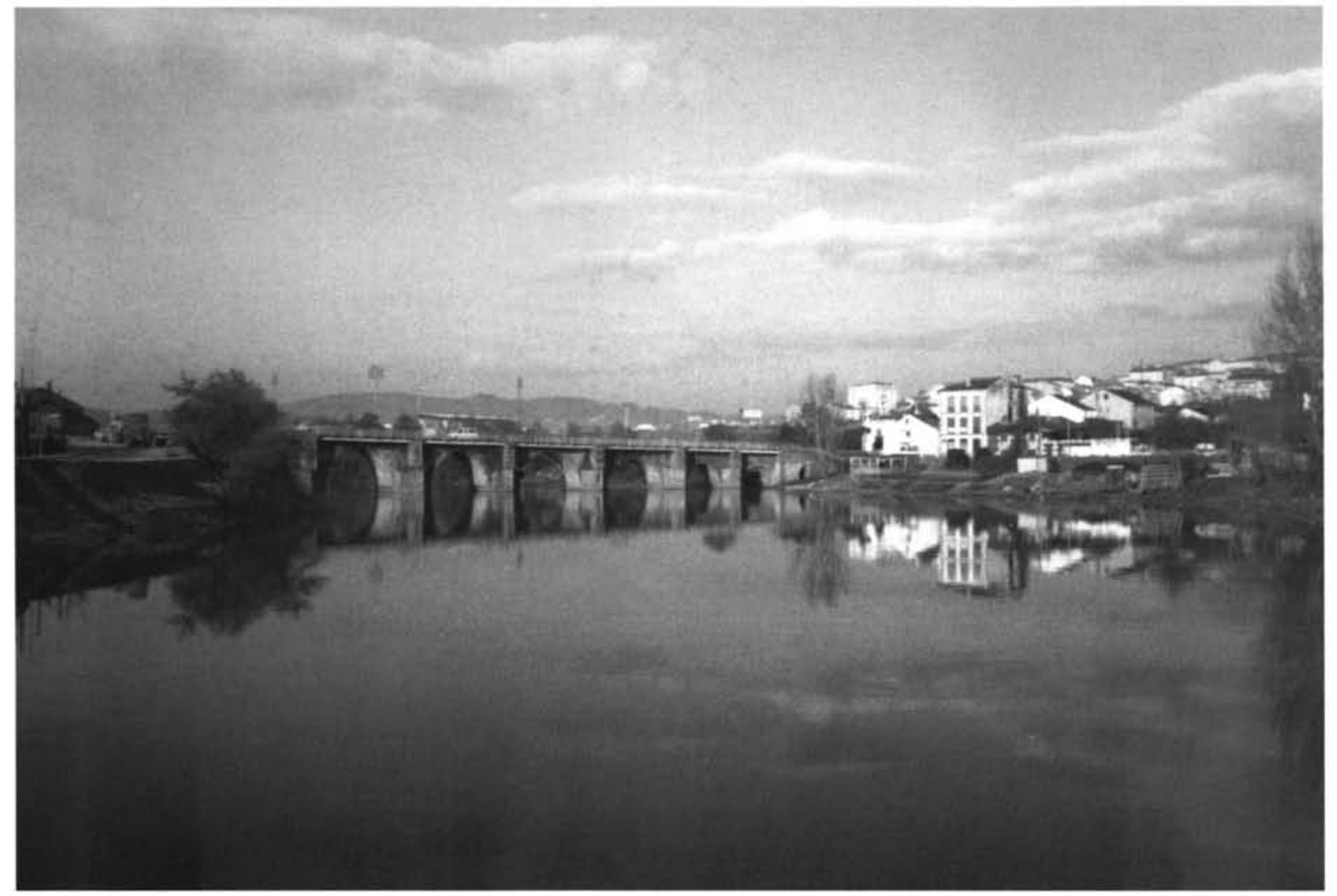

Lámina V. Marcie- Luco Augusti: Puente romano de Lugo (foto B. Sáez Taboada). 


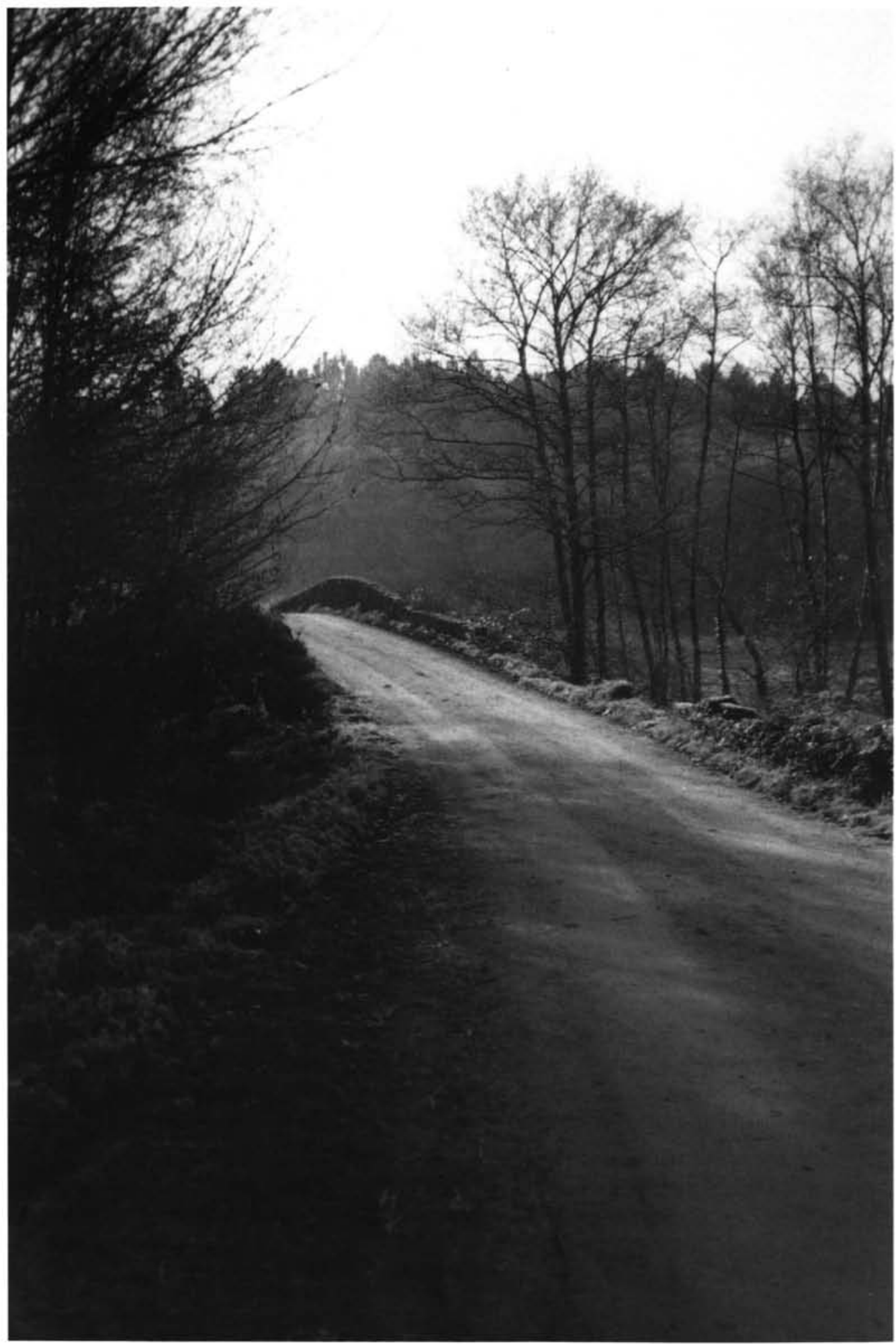

Lámina VI. Luco Augusti - Timalino: Puente Galiñeiros (foto B. Sáez Taboada). 